\title{
Thromboxane Synthase Is Preferentially Conserved in Activated Mouse Peritoneal Macrophages
}

\author{
Catherine S. Tripp, Kathleen M. Leahy, and Philip Needleman \\ Department of Pharmacology, Washington University School of Medicine, St. Louis, Missouri 63110
}

\begin{abstract}
Resident macrophages isolated from uninfected animals produce large quantities of arachidonic acid (AA) metabolites. Immunizing animals with protein antigens or bacteria activates macrophages and causes an $80 \%$ reduction in the cyclooxygenase and lipoxygenase metabolites relative to resident cells. Since some products have been shown to modulate immune functions, we examined how the AA metabolic enzyme activities regulate the products that are synthesized. We demonstrate that the cyclooxygenase, 5-lipoxygenase, prostacyclin synthase, and probably prostaglandin (PG) endoperoxide E-isomerase activities were decreased in activated peritoneal macrophages. In sharp contrast, thromboxane synthase activity was selectively unchanged or enhanced in the activated macrophages. Thus the immune response appears to modulate the activity of the AA and PG endoperoxide-dependent enzymes, thus dictating a major shift in the profile of metabolites synthesized by macrophages.
\end{abstract}

\section{Introduction}

Humes et al. (1) have demonstrated that resident macrophages produce 10-20-fold greater quantities of prostaglandin $E_{2}$ $\left(\mathrm{PGE}_{2}\right)^{1}$ and prostacyclin $\left(\mathrm{PGI}_{2}\right)$, measured as 6-keto-prostaglandin $F_{1 \alpha}\left(6-k e t o-P G F_{1 \alpha}\right)$, in response to zymosan stimulation than activated macrophages isolated from mice treated with thioglycollate, Cornebacterium parvum (C. parvum), or bacille Calmette-Guerin. Thioglycollate-elicited macrophages exhibited only $10 \%$ of the phospholipase activity, measured as $\left[{ }^{3} \mathrm{H}\right]$ arachidonic acid (AA) release, seen in prelabeled resident cells. Scott et al. (2) found that the zymosan-stimulated

This work was presented in part at the Winter Prostaglandin Conference in January, 1985, and at the Federation of American Societies for Experimental Biology meeting in April, 1985.

Address correspondence to Dr. Needleman.

Received for publication 8 March 1985.

1. Abbreviations used in this paper: AA, arachidonic acid; $C$. parvum, Cornebacterium parvum; HETE, monohydroxyeicosatetrienoic acid; HPLC, high performance liquid chromatography; 6-keto-PGF $F_{1 \alpha}$, 6-keto-prostaglandin $\mathrm{F}_{1 \alpha} ; \mathrm{LTC}_{4}$, leukotriene $\mathrm{C}_{4} ; \alpha$-MEM, $\alpha$-minimal essential media; PG, prostaglandin; $\mathrm{PGE}_{2}, \mathrm{PGF}_{2 \alpha}, \mathrm{PGH}_{2}$, prostaglandins $E_{2}, P_{2 \alpha}$, and $H_{2} ; P I_{2}$, prostacyclin; $P / S$, penicillin/streptomycin; $T_{x A}$, thromboxane $A_{2} ; T_{x B_{2}}$, thromboxane $B_{2}$.

J. Clin. Invest.

(c) The American Society for Clinical Investigation, Inc. 0021-9738/85/08/0898/04 \$1.00

Volume 76, August 1985, 898-901 production of leukotriene $\mathrm{C}_{4}\left(\mathrm{LTC}_{4}\right)$ and monohydroxyeicosatetrienoic acids (HETEs) as well as $\mathrm{PGE}_{2}$ and 6-keto-PGF $\mathrm{PG}_{1 \alpha}$ were decreased in $C$. parvum-elicited macrophages when compared with resident cells. Paradoxically, the quantity of thromboxane $A_{2}\left(T x A_{2}\right)$, measured as thromboxane $B_{2}\left(T x B_{2}\right)$, was increased in the $C$. parvum-elicited macrophages. In this report we have evaluated the $\mathrm{AA}$ and prostaglandin $\mathrm{H}_{2}\left(\mathrm{PGH}_{2}\right)$ dependent metabolic enzymes in resident and Listeria monocytogenes-elicited macrophages (Listeria macrophages) to characterize the preferential conservation of $\mathrm{TxA}_{2}$ production by macrophages during an immune response.

\section{Methods}

Macrophages were obtained by lavage from the peritoneal cavity of adult BIO.A/Sg Sn J mice (The Jackson Laboratory, Bar Harbor, ME) that were either uninfected (resident macrophages) or infected with Listeria monocytogenes (Listeria macrophages). Mice were infected intraperitoneally with $5 \times 10^{4}$ live bacteria on day 1 , boosted with $1 \times 10^{5}$ live bacteria on day 7 , and peritoneal exudates were collected on day 10 by lavaging with $3 \mathrm{ml}$ sterile phosphate-buffered saline (PBS). 1-2 $\times 10^{6}$ peritoneal cells were allowed to adhere to $35-\mathrm{mm}$ tissue culture dishes for $2 \mathrm{~h}\left(37^{\circ} \mathrm{C}, 5 \% \mathrm{CO}_{2}\right)$ in $1 \mathrm{ml}$ of $\alpha$-minimal essential media ( $\alpha$-MEM; Gibco Laboratories, Grand Island, NY), 5\% fetal calf serum, and $100 \mu \mathrm{g}$ penicillin/streptomycin (P/S). The nonadherent cells were removed by washing with PBS, and the adherent cells were incubated with various doses of agonists, substrates, or inhibitors in $\alpha$-MEM and P/S for $2 \mathrm{~h}\left(37^{\circ} \mathrm{C}, 5 \% \mathrm{CO}_{2}\right)$. Zymosan (Sigma Chemical Co., St. Louis, MO) was prepared as described by Bonney et al. (3). AA (Nu-Chek Prep., Inc., Elysian, MN) was dissolved using dimethylsulfoxide and then diluted with $\alpha$-MEM and P/S. Dimethylsulfoxide had no effect on cellular morphology or protein content. $30 \mu \mathrm{M}$ AA caused a $50 \%$ reduction in cellular protein after $2 \mathrm{~h}$ because of cells detaching from the plate. The cells that remained on the plate excluded trypan blue.

$\mathrm{PGH}_{2}$ was prepared from sheep seminal vesicles and $\mathrm{AA}(4)$ and stored in dry acetone at $-70^{\circ} \mathrm{C}$. Immediately before addition to macrophage cultures, $\mathrm{PGH}_{2}$ was dried under nitrogen and resolubilized in dimethylsulfoxide. Various aliquots of $\mathrm{PGH}_{2}$ in dimethylsulfoxide were added directly to macrophage cultures containing $1 \mathrm{ml}$ of $\alpha \mathrm{MEM}$ and $\mathrm{P} / \mathrm{S}$. The cells were incubated for $30 \mathrm{~min}$ at $22-25^{\circ} \mathrm{C}, 5 \% \mathrm{CO}_{2}$.

The media was analyzed for 6-keto-PGF $1 \alpha, \mathrm{PGE}_{2}, \mathrm{TxB}_{2}$, and $\mathrm{LTC}_{4}$ by radioimmunoassay (RIA) $(5,6)$. Antibodies to 6-keto-PGF ${ }_{1 \alpha}$ and LTC $_{4}$ were kindly supplied by Dr. Richard Fertel, Ohio State University, Columbus, $\mathrm{OH}$, and by Dr. Alan Rosenthal, Merck Sharp \& Dohme Research Laboratories, Rahway, NJ, respectively. Duplicate stimulations within a given experiment resulted in RIA values that were not discernibly different. The cross-reactivity at $50 \%$ displacement of other arachidonate metabolites with antisera were as follows: $P_{G E}$ antiserum: 6-keto-PGF $1 \alpha, 0.39 \%$; prostaglandin $\mathrm{F}_{2 \alpha}\left(\mathrm{PGF}_{2 \alpha}\right), 0.04 \%$; $\mathrm{TxB}_{2}, 0.003 \%$; 6-keto-PGF ${ }_{1 \alpha}$ antiserum: $\mathrm{PGE}_{2}, 0.57 \%$; $\mathrm{PGF}_{2 \alpha}, 0.14 \%$; $\mathrm{TxB}_{2},<0.08 \%$; $\mathrm{TxB}_{2}$ antiserum: 6-keto-PGF $\mathrm{PG}_{1 \alpha}, 0.009 \% ; \mathrm{PGE}_{2}, 0.012 \%$; $\mathrm{PGF}_{2 \alpha}, 0.025 \%$; and $\mathrm{LTC}_{4}$ antiserum: leukotriene $\mathrm{D}_{4}, 43 \%$; leukotriene $\mathrm{E}_{4}, 6 \%$; leu- 
kotriene $\mathrm{B}_{4}, \mathrm{PGE}_{2}, \mathrm{PGF}_{2 \alpha}, \mathrm{AA}$, and 5-HETE, $<0.25 \%$. The production of $\mathrm{LTC}_{4}$ by macrophages was also semiquantitated using high performance liquid chromatography (HPLC) and structurally verified using scanning ultraviolet spectroscopy between wavelengths 250 and 300 $\mathrm{nm}$. The amounts of $\mathrm{LTC}_{4}$ produced by the macrophage cultures quantitated by HPLC and RIA were similar. The cells were washed with PBS and solubilized in $0.62 \mathrm{~N} \mathrm{NaOH}$ for protein determination using the fluorescamine assay. All protein values in a given cell preparation were within $10 \%$ of each other. $1-2 \times 10^{6}$ cells corresponds to 50-100 $\mu \mathrm{g}$ protein. The data is represented as the mean $\pm \mathrm{SE}$ (7).

\section{Results}

Zymosan stimulation of total endogenous AA metabolism (sum of all the measured cyclooxygenase and lipoxygenase products) was decreased by $94 \%$ in Listeria macrophages (Fig. 1), findings comparable to those previously reported (1, 2). Listeria macrophages produced 2,10 , and $4 \%$ of the amount of 6-keto-PGF $1 \alpha, \mathrm{PGE}_{2}$, and $\mathrm{LTC}_{4}$, respectively, compared with resident cells. However, not only was $\mathrm{TxB}_{2}$ produced by resident mouse peritoneal macrophages but the $\mathrm{TxB}_{2}$ production in Listeria macrophages was not significantly different (71\%) from resident controls. In agreement with Scott et al. (2), we found that the resident macrophages produced small quantities of a product that co-migrated on HPLC with authentic 12-HETE, whereas Listeria macrophages did not produce any measurable 12-HETE (data not shown). No other lipoxygenase products were detected by either cell population. Thus the similar quantity of $\mathrm{TxB}_{2}$ produced by the two macrophage populations was due to synthesis by the macrophages and not to platelets contaminating the cultures, because (a) zymosan does not stimulate platelet AA metabolism (8), and $(b)$ the disappearance of the other potential major platelet lipoxygenase metabolite, 12-HETE, in Listeria macrophage preparation is not consistent with platelet contamination and stimulation.

Since the phospholipase(s) activity had been shown to be decreased in bacterial-elicited macrophages (1), we bypassed the need for receptor activation or stimulation of phospholi-

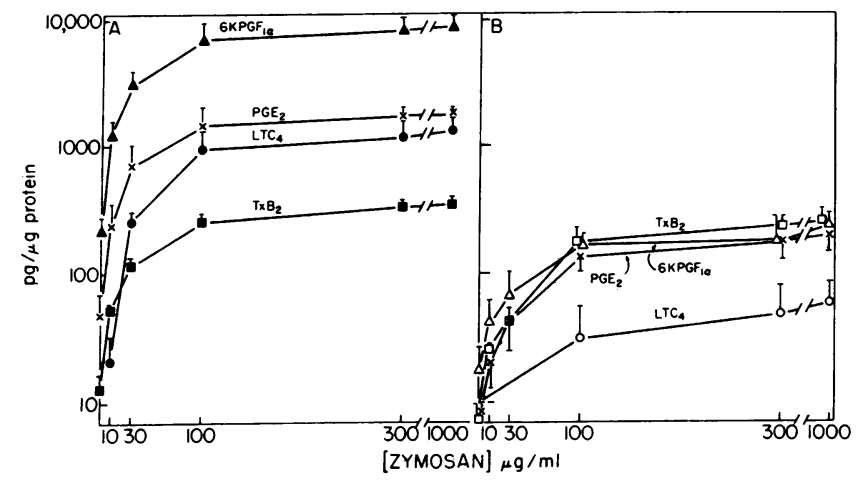

Figure 1. Comparison of zymosan stimulation of AA metabolism in resident and Listeria macrophages. Resident $(A)$ or Listeria $(B)$ mouse peritoneal macrophages were cultured and stimulated with varying concentrations of zymosan as described in Methods. The media was analyzed by RIA for 6-keto-PGF ${ }_{1 \alpha}\left(6 \mathrm{KPGF}_{1 \alpha}\right)(\Delta), \mathrm{TxB}_{2}$ $(\bowtie), \mathrm{PGE}_{2}(\times)$, and $\mathrm{LTC}_{4}(\bullet)$. Resident macrophages are represented by closed symbols and Listeria macrophages by open symbols. The data represent the mean $\pm \mathrm{SE}$ of four different macrophage preparations. pase(s) by incubating exogenous AA with each macrophage population. Total exogenous AA metabolism by the cyclooxygenase pathway (sum of $\mathrm{PGE}_{2}, \mathrm{TxB}_{2}$, and 6-keto-PGF $\mathrm{PG}_{1 \alpha}$ ) in Listeria macrophages was only $13 \%$ of that by resident cells, indicating that the cyclooxygenase activity was substantially decreased in the bacteria-elicited macrophages. Again, the quantity of 6-keto-PGF P $_{1 \alpha}$ produced by Listeria macrophages was only 5 and $27 \%$, respectively, while $71 \%$ of the $\mathrm{TxB}_{2}$ production was still maintained (Fig. 2).

Exogenous AA conversion by the 5-lipoxygenase pathway $\left(\mathrm{LTC}_{4}\right)$ was also decreased by $87 \%$ in Listeria macrophages (Fig. 2). However, zymosan stimulation produced tenfold more $\mathrm{LTC}_{4}$ than exogenous AA. Thus differences in the 5-lipoxygenase activity between the two cell populations is more easily detected using zymosan as an agonist. Furthermore, zymosanstimulated $\mathrm{LTC}_{4}$ production should be enhanced in the presence of indomethacin, which inhibits cyclooxygenase and blocks $\mathrm{PGE}_{2}, \mathrm{PGI}_{2}$, and $\mathrm{TxA}_{2}$ production. Pretreatment of resident macrophages with indomethacin diverted endogenous AA into the lipoxygenase pathway after zymosan stimulation (Fig. 3). However, Listeria macrophages still did not exhibit an increase in the 5-lipoxygenase metabolite $\mathrm{LTC}_{4}$ (Fig. 3). When the samples were analyzed for other 5-lipoxygenase products (5-HETE and 5,12-diHETEs, data not shown) by HPLC, none of these nonenzymatic products of the 5-lipoxygenase could be detected even in the presence of indomethacin, though more substrate was available for conversion by this pathway. Thus the 5-lipoxygenase activity must be suppressed in Listeria macrophages since the amount of 5-lipoxygenase product $\mathrm{LTC}_{4}$ is decreased and no other nonenzymatic products are detectable.

The synthesis of $\mathrm{PGE}_{2}, \mathrm{PGI}_{2}$, and $\mathrm{TxA}_{2}$ each requires the sequential action of three enzymes: phospholipase, cyclooxygenase, and the appropriate prostaglandin (PG) endoperoxidedependent enzyme. When exogenous $\mathrm{PGH}_{2}$ was used as substrate for $\mathrm{PGI}_{2}$ synthase, Listeria macrophages still demonstrated only $5 \%$ of the 6-keto-PGF la $_{\alpha}$ production seen with resident macrophages (Fig. 4). The enzymatic production of $\mathrm{PGE}_{2}$ could not be measured due to the extensive nonenzymatic

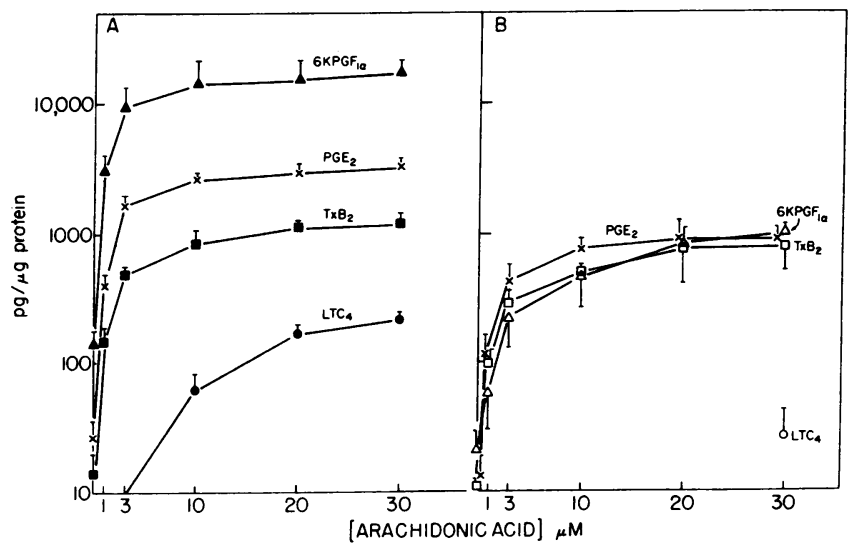

Figure 2. Comparison of exogenous AA metabolism by resident and Listeria macrophages. Cultured resident $(A)$ and Listeria $(B)$ macrophages were stimulated with various concentrations of AA. The media was analyzed by RIA for 6-keto-PGF $1 \alpha\left(6 \mathrm{KPGF}_{1 \alpha}\right)(\Delta), \mathrm{TxB}_{2}$ $(\bullet), \mathrm{PGE}_{2}(\times)$, and $\mathrm{LTC}_{4}(\bullet)$. Resident macrophages are represented by open symbols and Listeria macrophages by closed symbols. The data represent the mean $\pm S E$ of four separate macrophage cultures. 


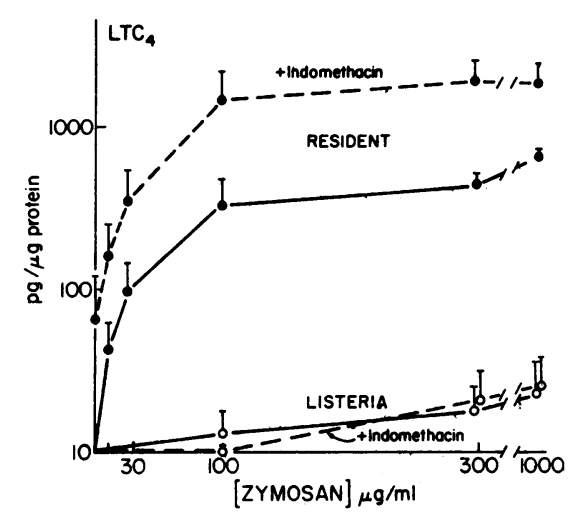

Figure 3. The synthesis of $\mathrm{LTC}_{4}$ by Listeria macrophages cannot be enhanced with indomethacin. Macrophage cultures were obtained and stimulated with zymosan as described, except that after adherence macrophages were preincubated for $15 \mathrm{~min}\left(37^{\circ} \mathrm{C}, 5 \% \mathrm{CO}_{2}\right)$ in $\alpha$-MEM and P/S in the presence (-s---) or absence (-) of $5 \mu \mathrm{g} / \mathrm{ml}$ indomethacin (Merck Sharp \& Dohme Research Laboratories). The stimulation of the cyclooxygenase products in the absence of indomethacin was comparable to that seen in Fig. 1 but was inhibited to basal values (no zymosan) in the presence of indomethacin. Resident macrophages are represented by closed symbols and Listeria macrophages by open symbols. The data represent the mean \pm SE of three macrophage culture preparations.

conversion of $\mathrm{PGH}_{2}$ to $\mathrm{PGE}_{2}$ obtained in aqueous solution (no cells). However, using $\mathrm{PGH}_{2}$ as substrate for the direct measurement of thromboxane synthase activity unmasked a $250 \%$ increase in $\mathrm{TxB}_{2}$ production in Listeria macrophages. This increase in thromboxane synthase activity accounts for the relatively unchanged $\mathrm{TxB}_{2}$ production in response to endogenous (zymosan-stimulated) and exogenous AA metab-

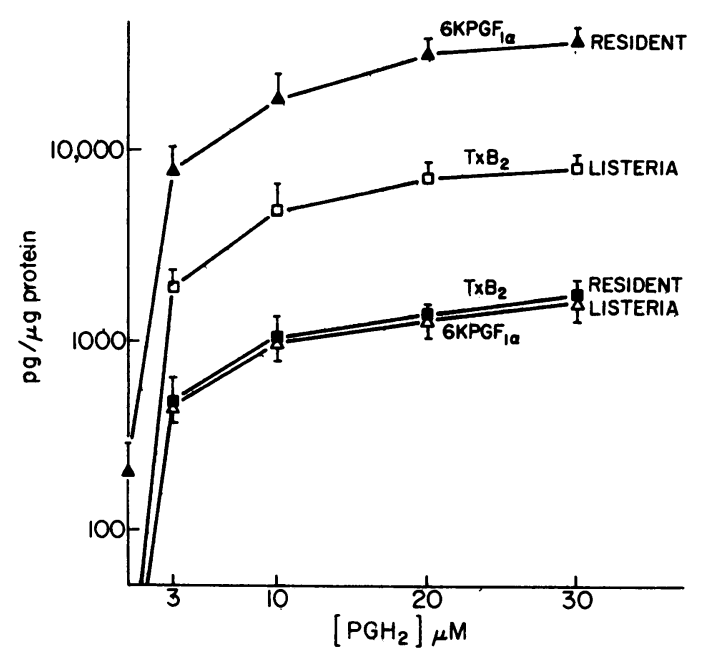

Figure 4. Comparison of exogenous $\mathrm{PGH}_{2}$ metabolism by resident and Listeria macrophages. Cultured resident and Listeria macrophages were incubated with varying concentrations of $\mathrm{PGH}_{2}$ as described. The media was analyzed for 6-keto-PGF ${ }_{1 \alpha}\left(6 \mathrm{KPGF}_{1 \alpha}\right)(\Delta)$ and $\operatorname{TxB}_{2}(\square)$ by RIA. The $\mathrm{PGE}_{2}$ cross-reactivity of the 6-keto-PGF and $\mathrm{TxB}_{2}$ antibodies represents $3 \%$ or less of the metabolite production. Resident macrophages are represented by closed symbols and Listeria macrophages by open symbols. The data represent the mean $\pm S E$ of four separate macrophage cultures. olism by Listeria macrophages. Furthermore, if the cyclooxygenase activity were the same in both cell populations, then this increased $\mathrm{TxB}_{2}$ production should have been seen with exogenous AA. Since $\mathrm{TxB}_{2}$ was slightly decreased in Listeria macrophages in response to exogenous AA (Fig. 2 B) but increased in response to exogenous $\mathrm{PGH}_{2}$ (Fig. 4), then the cyclooxygenase activity must be decreased in the Listeria cells, limiting the amount of $\mathrm{PGH}_{2}$ available for conversion by the thromboxane synthase. Although the PG endoperoxide E-isomerase activity could not be measured directly with $\mathrm{PGH}_{2}$ stimulation, this enzyme is also likely to be decreased in Listeria macrophage since the $\mathrm{PGE}_{2}$ production was greatly decreased in these cells in response to zymosan or exogenous AA (Figs. 1 and 2). Thromboxane was the only metabolite conserved in Listeria macrophages,

\section{Discussion}

Macrophages isolated from Listeria monocytogenes-treated mice have been shown to be cytocidal (9) and to express Ia antigen (10). Here we report that AA metabolism by Listeria macrophages has been altered in such a way that $\mathrm{PGE}_{2}$ and $\mathrm{PGI}_{2}$ production was greatly decreased while $T \times A_{2}$ production was maintained. In cultured Listeria macrophages, exogenous $\mathbf{P G I}_{2}$ and dibutyrl cyclic AMP (cAMP) have been shown to inhibit Ia expression. In addition, in vivo treatment with $\mathrm{PGE}_{1}$ and $\mathrm{PGE}_{2}$ blocks lymphokine-stimulated macrophage Ia expression (11). $\mathrm{PGE}_{2}$ inhibits macrophage cytolytic activity (12) and interleukin-1 secretion (13) in vitro as well. Snyder et al. (11) have demonstrated that in vitro treatment of macrophages with $\mathrm{TxB}_{2}$ (the inactive metabolite of $\mathrm{TxA}_{2}$ ) antagonizes $\mathrm{PGE}_{2}$ inhibition of Ia expression, but $\mathrm{TxB}_{2}$ itself has no effect on the expression of Ia. Thus it has been proposed that increased immune function can result by a decreased production of the negative immunomodulator $\mathrm{PGE}_{2}$. However, $\mathbf{P G I}_{2}$ is also produced in large quantities in resident macrophages but decreased by $95 \%$ in activated cells. $\mathrm{PGI}_{2}$ has also been shown to be a more potent stimulator of cAMP in platelets than $\mathrm{PGE}_{2}$ (14) and therefore may be an important negative immunomodulator as well.

Finally, $\gamma$-interferon has been shown to modulate macrophage Ia expression as well as macrophage phospholipase activity. Boraschi et al. $(13,15)$ have reported that resident macrophages cultured with $\alpha-, \beta$-, and $\gamma$-interferons have decreased phospholipase activity, but they do not exhibit changes in AA metabolic enzyme activities within $24 \mathrm{~h}$. Beller and $\mathrm{Ho}(16)$ have demonstrated that $\gamma$-interferon increases Ia expression over a 4-8-d culture period. Furthermore, Johnson and Torres have reported that leukotrienes may regulate the production of $\gamma$-interferon by $T$ cells (17). In this report we report that immune activation of macrophages in vivo suppressed all of the AA and PG endoperoxide-dependent enzymes with the exception of thromboxane synthase. The result of these AA metabolic enzyme alterations was that the ratio of $\mathrm{TxA}_{2} / \mathrm{PGI}_{2} / \mathrm{PGE}_{2}$ production (when stimulated with an agonist) by Listeria macrophages was 1:1:1 compared with $1: 25: 5$ in resident cells. Since $\mathrm{TxA}_{2}$ and $\mathrm{PGI}_{2} / \mathrm{PGE}_{2}$ have been shown to have opposing biologies on the vasculature and platelet aggregation, the ratio of product determined the final biology expressed. We propose that $\gamma$-interferon might be responsible for the modulation of the AA metabolic enzymes described in this paper and that the regulation of Ia expression by $\gamma$ - 
interferon might be mediated through the stimulatory effects of $\mathrm{TxA}_{2}$ production, as well as the removal of the inhibitory effects of $\mathrm{PGE}_{2}$ and $\mathrm{PGI}_{2}$.

\section{Acknowledgments}

The authors would like to thank Dr. John Russell and Dr. Barbara Jakschik for invaluable assistance.

This work was supported by National Institutes of Health grants HL07275 and HL20787.

\section{References}

1. Humes, J. L., S. Burger, M. Galavage, F. A. Kuehl, Jr., D. D. Wightman, M. E. Dahlgren, P. Davies, and R. J. Bonney. 1980. The diminished production of arachidonic acid oxygenation products by elicited mouse peritoneal macrophages: possible mechanisms. J. Immunol. 124:2110-2116.

2. Scott, W. A., N. A. Pawlowski, H. W. Murray, M. Andreach, S. Zrike, and Z. A. Cohn. 1982. Regulation of arachidonic acid metabolism by macrophage activation. J. Exp. Med. 155:1148-1160.

3. Bonney, R. J., P. D. Wightman, P. Davies, S. J. Sadowski, F. A. Kuehl, Jr., and J. L. Humes. 1978. Regulation of prostaglandin synthesis and of selective release of lysosomal hydrolases by mouse peritoneal macrophages. Biochem. J. 176:433-442.

4. Gorman, R. R., F. F. Sun, O. V. Miller, and R. A. Johnson. 1977. Prostaglandins $H_{1}$ and $H_{2}$. Convenient biochemical synthesis and isolation. Further biological and spectroscopic characterization. Prostaglandins. 13:1043-1056.

5. Felsen Reingold, D., K. Watters, S. Holmberg, and P. Needleman 1981. Differential biosynthesis of prostaglandins by hydronephrotic rabbit and cat kidneys. J. Pharmacol. Exp. Ther. 216:510-515.

6. Hayes, E. C., D. L. Lombardo, Y. Girard, A. L. Maycock, J. Rockach, A. S. Rosenthal, R. N. Young, R. W. Egan, and H. J. Zweekink. 1983. Measuring leukotrienes of slow reacting substance of anaphylaxis: development of a specific radioimmunoassay. J. Immunol. 131:429-433.

7. Colton, T. 1974. Statistics in Medicine. Little, Brown \& Co., Boston. 137-138.

8. Pawlowski, N., G. Kaplan, A. L. Hamill, Z. A. Cohn, and W. A. Scott. 1983. Arachidonic acid metabolism by human monocytes. J. Exp. Med. 158:393-412.

9. Farr, A. G., W. J. Wechter, J.-M. Kiely, and E. R. Unanue. 1979. Induction of cytocidal macrophages-role of H-2. J. Immunol. 122:2405-2412.

10. Beller, D. I., J.-M. Kiely, and E. R. Unanue. 1980. Regulation of macrophage populations. Preferential induction of Ia rich peritoneal exudates by immunologic stimuli. J. Immunol. 124:1426-1432.

11. Snyder, D. S., D. I. Beller, and E. R. Unanue. 1982. Prostaglandins modulate macrophage Ia expression. Nature (Lond.) 299:163165.

12. Taffet, S. M., and S. W. Russell. 1981. Macrophage-mediated tumor cell killing: regulation of expression of cytolytic activity by prostaglandin E. J. Immunol. 126:424-427.

13. Boraschi, D., S. Censini, and A. Tagliabue. 1984. Interferon- $\gamma$ reduces macrophage-suppressive activity by inhibiting prostaglandin $\mathrm{E}_{2}$ release and inducing interleukin 1 production. J. Immunol. 133: 764-768.

14. Gorman, R. R., S. Bunting, and O. V. Miller. 1977. Modulation of human platelet adenylate cyclase by prostacyclin (PGX). Prostaglandins. 13:377-388.

15. Boraschi, D., S. Censini, M. Bartalini, G. Scapigliati, G. Barbarulli, E. Vincenzi, M. Benedetta Donati, and A. Tagliabue. 1984. Interferon inhibits prostaglandin biosynthesis in macrophages: effects on arachidonic acid metabolism. J. Immunol. 132:1987-1992.

16. Beller, D. I., and K. Ho. 1982. Regulation of macrophage populations. V. Evaluation of the control of macrophage la expression in vitro. J. Immunol. 129:971-976.

17. Johnson, H. M., and B. A. Torres. 1984. Leukotrienes: positive signals for regulation of $\gamma$-interferon production. J. Immunol. 132: 413-416. 